\title{
High-Flow Nasal Cannula May Not Reduce the Re-Intubation Rate Compared With a Large-Volume Nebulization-Based Humidifier
}

\author{
Wataru Matsuda, Akiyoshi Hagiwara, Tatsuki Uemura, Takunori Sato, Kentaro Kobayashi, \\ Ryo Sasaki, Tatsuya Okamoto, and Akio Kimura
}

\begin{abstract}
BACKGROUND: High-flow nasal cannula (HFNC) therapy may reduce the re-intubation rate compared with conventional oxygen therapy. However, HFNC has not been sufficiently compared with conventional oxygen therapy with a heated humidifier, even though heated humidification is beneficial for facilitating airway clearance. METHODS: This study was a single-center, open-label, randomized controlled trial. We randomized subjects with respiratory failure after extubation to either HFNC group or to a large-volume humidified nebulization-based nebulizer. The primary end point was the re-intubation rate within $7 \mathrm{~d}$ after extubation. RESULTS: We could not recruit enough subjects for the sample size we designed, therefore, we analyzed 69 subjects (HFNC group, 30 subjects; nebulizer group, 39 subjects). The re-intubation rate within 7 d was not significantly different between the HFNC and nebulizer groups $(5 / 30$ subjects $[17 \%]$ and 6/39 subjects [15\%], respectively; $P>$.99). $\mathrm{P}_{\mathrm{aO}_{2}} / \mathrm{set} \mathrm{F}_{\mathrm{IO}_{2}}$ at $24 \mathrm{~h}$ after extubation was also not significantly different between the respective groups $(264 \pm 105 \mathrm{~mm} \mathrm{Hg}$ in the HFNC group vs 224 $\pm 53 \mathrm{~mm} \mathrm{Hg}$ in the nebulizer group; $P=.07)$. CONCLUSIONS: Compared with a large-volume nebulization-based humidifier, HFNC may not reduce the re-intubation rate within $7 \mathrm{~d}$. However, because of insufficient statistical power, further studies are needed to reach a conclusion. Key words: respiratory insufficiency; respiratory therapy; tracheal extubation; weaning; high-flow nasal cannula; humidification; ventilators; oxygen inhalation therapy; hypoxia; re-intubation. [Respir Care 2020;65(5):610-617. (C) 2020 Daedalus Enterprises]
\end{abstract}

\section{Introduction}

High-flow nasal cannula (HFNC) oxygen therapy provides high-flow gas delivery compared with conventional devices. High-flow delivery of gas in HFNC is achieved by means of a heated humidifier. Thus, HFNC has two

Drs Matsuda, Uemura, Sato, Kobayashi, Sasaki, and Kimura are affiliated with the Department of Emergency Medicine and Critical Care, Center Hospital of the National Center for Global Health and Medicine, Shinjuku-ku, Tokyo, Japan. Dr Hagiwara is affiliated with the Department of Emergency Medicine, Niizashiki Chuo General Hospital, Niiza-shi, Saitama, Japan. Dr Okamotoa is affiliated with the Department of Intensive Care Medicine, Center Hospital of the National Center for Global Health and Medicine, Shinjuku-ku, Tokyo, Japan.

Dr Matsuda presented a version of this paper at the 46th Annual Meeting of the Japanese Association for Acute Medicine held November 19, 2018, in Yokohama, Japan, and at the 46th Annual Meeting of the Japanese Society of Intensive Care Medicine held March 1, 2019, in Kyoto, Japan. advantages: heated humidification and mild positive airway pressure due to high flow. Because of the high flow, the settings for the HFNC device are more precise in terms of $\mathrm{F}_{\mathrm{IO}_{2}}$ than are other devices. ${ }^{1}$ HFNC is also expected to have the effects of reducing the work of breathing ${ }^{2-5}$ and of improving alveolar recruitment ${ }^{6}$ by using a mild positive airway pressure. ${ }^{7,8}$

\footnotetext{
This study was supported in part by a Grant-in-Aid for Research from the National Center for Global Health and Medicine (29-2001). The funding source had no role in study design, the collection, analysis, or interpretation of data, or the preparation, review, or approval of the manuscript. We used this funding source only for manuscript preparation in English.
}

The authors have disclosed no conflicts of interest.

The basic information of this study have been registered on a registry University Hospital Medical Information Network Clinical Trials Registry (UMIN000019238). 
Maggiore et $\mathrm{al}^{9}$ conducted a randomized controlled trial to compare the effectiveness of HFNC versus an airentrainment mask after extubation in adult subjects with respiratory failure. The primary outcome of their study was $\mathrm{P}_{\mathrm{aO}_{2}} / \mathrm{set} \mathrm{F}_{\mathrm{IO}_{2}}$ at $24 \mathrm{~h}$ after extubation, which was significantly higher in the HFNC group. The set $\mathrm{F}_{\mathrm{IO}_{2}}$ was defined as the set $\mathrm{F}_{\mathrm{IO}_{2}}$ in oxygen therapies. The re-intubation rate, a secondary outcome, was also significantly lower. In addition, a multi-center randomized controlled trial recently showed a significantly reduced re-intubation rate with HFNC versus nasal cannula or non-rebreather face mask in subjects who are critically ill and at low risk of reintubation. ${ }^{10}$

In these 2 trials ${ }^{9,10}$ however, HFNC therapy was compared with conventional oxygen therapies without a heated humidifier. For this reason, we believe that the subjects benefitted from the effectiveness of not only high flow but also heated humidification at the same time. Humidification of gas delivered to patients is beneficial for improving airway clearance. ${ }^{11}$ Given that the re-intubation rate for airway failure was lower in the HFNC groups in the 2 trials, ${ }^{9,10}$ humidification with HFNC may have had a major impact on the outcomes. We considered that conventional oxygen therapies with a heated humidifier may be adequate without the need for high flows. Therefore, HFNC therapy should be compared with oxygen therapy using a heated humidifier, such as a large-volume nebulization-based humidifier, to evaluate whether high-flow gas is necessary to prevent re-intubation. A large-volume nebulization-based humidifier is a large-volume nebulizer that aerosolizes heated sterile water and delivers the aerosol to the patient via an adjustable Venturi valved connector. We hypothesized that HFNC therapy after extubation could reduce the re-intubation rate compared with a large-volume nebulization-based humidifier.

\section{Methods}

\section{Study Design}

This study was a single-center, open-label, randomized controlled trial conducted in an ICU in Japan. The ethics committee of our hospital approved the study, and written informed consent was obtained from the subjects or a proxy.

Correspondence: Wataru Matsuda MD, Department of Emergency Medicine and Critical Care, Center Hospital of the National Center for Global Health and Medicine, 1-21-1 Toyama, Shinjuku-ku, Tokyo 1628655, Japan. E-mail: wmatsuda@hosp.ncgm.go.jp.

DOI: $10.4187 /$ respcare.07095

\section{QUICK LOOK}

\section{Current knowledge}

High-flow nasal cannula (HFNC) therapy could reduce the re-intubation rate compared with conventional oxygen therapies without a heated humidifier. However, HFNC has not been sufficiently compared with conventional oxygen therapy with a heated humidifier, even though heated humidification is important to facilitate airway clearance.

\section{What this paper contributes to our knowledge}

Compared with a large-volume nebulization-based humidifier, HFNC may not reduce the re-intubation rate within $7 \mathrm{~d}$ after extubation in subjects with respiratory failure.

\section{Inclusion and Exclusion Criteria}

Patients age $\geq 18$ y who had received conventional mechanical ventilation for $>24 \mathrm{~h}$ in the emergency department were screened for enrollment. Patients were eligible for inclusion if they successfully passed a spontaneous breathing trial (SBT) and had a $\mathrm{P}_{\mathrm{aO}_{2}} / \mathrm{set}_{\mathrm{IO}_{2}}<300 \mathrm{~mm} \mathrm{Hg}$ within $3 \mathrm{~h}$ before extubation. Exclusion criteria were as follows: (1) difficulty with attaching the device safely, (2) pregnancy, (3) tracheostomy before enrollment, (4) pneumothorax without drainage, and (5) do-not-intubate order.

We evaluated whether extubation was possible according to SBT criteria based on a previous review. ${ }^{12}$ The recommendations of the relevant Japanese academic societies set individual thresholds for the SBT (https:// www.jsicm.org/pdf/kokyuki_ridatsu1503b.pdf, Accessed March 10, 2019). First, the SBT was started with the following ventilator settings: $\mathrm{F}_{\mathrm{IO}_{2}} \leq 0.4$, intermittent mandatory ventilation rate $\leq 2$ times/min, and pressure support $\leq$ $3 \mathrm{~cm} \mathrm{H}_{2} \mathrm{O}$. Second, the subjects were observed for $30-120$ min while on a T-piece or with CPAP of $\leq 5 \mathrm{~cm} \mathrm{H}_{2} \mathrm{O}$. If all of the following conditions were satisfied during the SBT, we considered it to be successful and then carried out extubation: breathing frequency $\leq 35$ breaths $/ \mathrm{min} ; \mathrm{S}_{\mathrm{pO}_{2}} \geq 90 \%$; heart rate $\leq 140$ beats/min or a change in heart rate of $<20 \%$ from baseline; systolic blood pressure $\geq 90 \mathrm{~mm}$ $\mathrm{Hg}$ and $\leq 180 \mathrm{~mm} \mathrm{Hg}$; tidal volume $\geq 5 \mathrm{~mL} / \mathrm{kg}$; no signs of discomfort, anxiety, and/or sweating; and breathing frequency/tidal volume $\leq 105$ breaths/min/L.

\section{Treatment Protocols}

Before extubation, all the subjects were randomized to receive oxygen therapy via HFNC (HFNC group) or a large-volume nebulization-based humidifier (nebulizer 


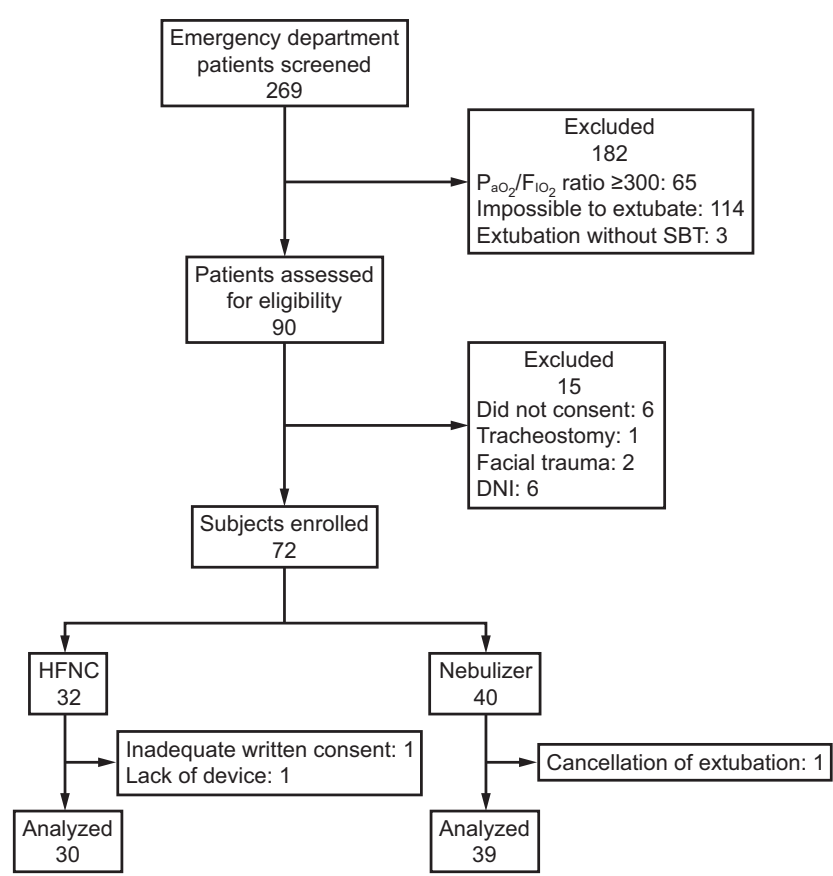

Fig. 1. Flow chart. SBT $=$ spontaneous breathing trial; $\mathrm{DNI}=$ do-not-intubate; HFNC = high-flow nasal cannula.

group). Randomization was done by independent staff according to a computer-generated assignment table. After extubation, we assigned the following protocol treatments to each subject according to the allocation. In both groups, we set the temperature of the heated humidifier according to the manufacturer's instructions. For the HFNC group, the initial set $\mathrm{F}_{\mathrm{IO}_{2}}$ was 0.4 , and the flow through the nasal cannula was $50 \mathrm{~L} / \mathrm{min}$. For the nebulizer group, a large-volume nebulization-based humidifier and a mask shaped to cover the lower half of the face were used. The initial set $\mathrm{F}_{\mathrm{IO}_{2}}$ was 0.4 , and the flow was adjusted according to tidal volume. $\operatorname{set} \mathrm{F}_{\mathrm{IO}_{2}}$ was designated to be automatically set by each device. However, for low-flow oxygen therapy systems, we used the following dose and $\mathrm{F}_{\mathrm{IO}_{2}}$ levels for the nasal cannula: $1 \mathrm{~L} / \mathrm{min}$ and $0.24,2 \mathrm{~L} / \mathrm{min}$ and $0.28,3 \mathrm{~L} / \mathrm{min}$ and 0.32 , and $4 \mathrm{~L} / \mathrm{min}$ and 0.36 ; and, for the simple face mask, these were as follows: 5-6 L/min and 0.4, and 7-8 L/min and 0.5.

In both groups, set $\mathrm{F}_{\mathrm{IO}_{2}}$ was adjusted to maintain $\mathrm{S}_{\mathrm{pO}_{2}}$ $\geq 95 \%$. However, for subjects in chronic respiratory failure, the attending physician adjusted the $\operatorname{set} \mathrm{F}_{\mathrm{IO}_{2}}$ to maintain an $\mathrm{S}_{\mathrm{pO}_{2}}$ of $88-95 \%$. Protocol treatments were continued for up to $48 \mathrm{~h}$. Oxygen therapy was terminated or changed to a normal nasal cannula if the required set $\mathrm{F}_{\mathrm{IO}_{2}}$ decreased to $<0.3$ because a large-volume nebulization-based humidifier could not deliver gas with an set $\mathrm{F}_{\mathrm{IO}_{2}} \leq 0.3$. The attending physician also discontinued the protocol treatment if oxygen therapy was needed after $48 \mathrm{~h}$ and considered using other oxygen therapies or
Table 1. Characteristics of Subjects at Baseline

\begin{tabular}{|c|c|c|c|}
\hline Characteristic & $\begin{array}{l}\text { HFNC } \\
\text { Group } \\
(n=30)\end{array}$ & $\begin{array}{l}\text { Nebulizer } \\
\text { Group } \\
(n=39)\end{array}$ & $P$ \\
\hline Age, mean \pm SD y & $72 \pm 18$ & $71 \pm 16$ & .83 \\
\hline Female, $n(\%)$ & $12(40)$ & $8(21)$ & .11 \\
\hline $\mathrm{BMI}$, mean $\pm \mathrm{SD} \mathrm{kg} / \mathrm{m}^{2}$ & $22 \pm 4$ & $21 \pm 4$ & .19 \\
\hline APACHE II score, mean \pm SD & $24 \pm 7$ & $22 \pm 6$ & .38 \\
\hline SOFA score, mean $\pm \mathrm{SD}$ & $8 \pm 3$ & $8 \pm 3$ & .88 \\
\hline $\begin{array}{l}\text { Length of mechanical ventilation } \\
\text { before extubation, mean } \pm \mathrm{SD} d\end{array}$ & $5 \pm 2$ & $6 \pm 3$ & .40 \\
\hline Heart rate, mean $\pm \mathrm{SD}$ beats/min & $78 \pm 23$ & $83 \pm 18$ & .31 \\
\hline $\begin{array}{l}\text { Mean artery pressure, mean } \pm \\
\text { SD mm Hg }\end{array}$ & $89 \pm 18$ & $90 \pm 17$ & .70 \\
\hline $\begin{array}{l}\text { Glasgow coma scale score }<15, \\
\quad n(\%)\end{array}$ & $22(73)$ & $30(77)$ & .78 \\
\hline $\begin{array}{l}\text { Breathing frequency, mean } \pm \\
\text { SD breaths/min }\end{array}$ & $18 \pm 5$ & $19 \pm 6$ & .25 \\
\hline $\mathrm{pH}$, mean $\pm \mathrm{SD}$ & $7.47 \pm 0.05$ & $7.46 \pm 0.05$ & .57 \\
\hline $\mathrm{P}_{\mathrm{aO}_{2}}$, mean $\pm \mathrm{SD}$ mm Hg & $76 \pm 13$ & $72 \pm 11$ & .12 \\
\hline $\mathrm{P}_{\mathrm{aCO}_{2}}$, mean $\pm \mathrm{SD}$ mm Hg & $44 \pm 7$ & $41 \pm 6$ & .10 \\
\hline $\mathrm{P}_{\mathrm{aCO}_{2}}>45, n(\%) \mathrm{mm} \mathrm{Hg}$ & $11(37)$ & $9(23)$ & .29 \\
\hline $\mathrm{P}_{\mathrm{aCO}_{2}} / \mathrm{F}_{\mathrm{IO} 2 \mathrm{set}}$, mean $\pm \mathrm{SD} \mathrm{mm} \mathrm{Hg}$ & $227 \pm 43$ & $216 \pm 37$ & .25 \\
\hline T-piece, $n(\%)$ & $0(0)$ & $4(10)$ & .13 \\
\hline \multicolumn{4}{|l|}{ Diagnosis, $n(\%)$} \\
\hline Respiratory infection & $17(57)$ & $20(51)$ & .81 \\
\hline Sepsis & $4(13)$ & $8(21)$ & .53 \\
\hline Acute heart failure & $1(3)$ & $2(5)$ & $>.99$ \\
\hline Other & $8(27)$ & $10(26)$ & $>.99$ \\
\hline \multicolumn{4}{|l|}{ History, $n(\%)$} \\
\hline COPD & $1(3)$ & $3(8)$ & .61 \\
\hline Chronic cardiac disease & $8(27)$ & $5(13)$ & .21 \\
\hline \multicolumn{4}{|c|}{$\begin{array}{l}\text { HFNC }=\text { high-flow nasal cannula } \\
\text { Nebulizer }=\text { a large volume nebulization-based humidifier } \\
\text { BMI }=\text { body mass index } \\
\text { APACHE = Acute Physiology and Chronic Health Evaluation } \\
\text { SOFA = sequential organ failure assessment }\end{array}$} \\
\hline
\end{tabular}

mechanical ventilation. If the following criteria were met, even at the maximum set $\mathrm{F}_{\mathrm{IO}_{2}}$ after extubation, then noninvasive ventilation or re-intubation was performed: breathing frequency $\geq 30$ breaths $/ \mathrm{min}, \mathrm{P}_{\mathrm{aO}}<70 \mathrm{~mm}$ $\mathrm{Hg}, \mathrm{pH}<7.3$, or $\mathrm{P}_{\mathrm{aCO}_{2}}>60 \mathrm{~mm} \mathrm{Hg}$. Re-intubation was performed if the respiratory status did not improve with noninvasive ventilation or if the subject showed evidence of airway obstruction, severe circulatory failure, cardiac arrest, or coma.

\section{Data}

We recorded the characteristics of each subject at enrollment, cause of respiratory failure, APACHE (Acute Physiology and Chronic Health Evaluation) II score, and SOFA (Sequential Organ Failure Assessment) score. We also recorded breathing frequency, $\mathrm{S}_{\mathrm{pO}_{2}}$, arterial blood gas 
Table 2. Main Outcomes

\begin{tabular}{|c|c|c|c|c|}
\hline Parameter & HFNC Group, $n / N(\%)$ & Nebulizer Group, $n / N(\%)$ & Odds Ratio (95\% CI) & $P$ \\
\hline Subjects & 30 & 39 & & \\
\hline Re-intubation within $7 \mathrm{~d}$ & $5 / 30(17)$ & $6 / 39(15)$ & $1.10(0.24-4.88)$ & $>.99$ \\
\hline \multicolumn{5}{|l|}{ Reason for the re-intubation } \\
\hline Sputum obstruction & $2 / 30(7)$ & $3 / 39(8)$ & & \\
\hline Hypoxia & $2 / 30(7)$ & $1 / 39(3)$ & & \\
\hline Shock & $0 / 30(0)$ & $2 / 39(5)$ & & \\
\hline Laryngeal edema & $1 / 30(3)$ & $0 / 39(0)$ & & \\
\hline Re-intubation within $48 \mathrm{~h}$ & $2 / 30(7)$ & $5 / 39(13)$ & $0.49(0.04-3.28)$ & .69 \\
\hline Re-intubation or NIV within $48 \mathrm{~h}$ & $2 / 30(7)$ & $8 / 39(21)$ & $0.28(0.03-1.58)$ & .17 \\
\hline \multicolumn{5}{|l|}{ Time using each device in subjects not re-intubated } \\
\hline $0-24 \mathrm{~h}$ & $2(7)$ & $11(28)$ & & \\
\hline $24-48 \mathrm{~h}$ & $13(43)$ & $16(41)$ & & \\
\hline \multirow[t]{2}{*}{$\geq 48 \mathrm{~h}$} & $13(43)$ & $7(18)$ & & \\
\hline & & & Difference $(95 \% \mathrm{CI})$ & \\
\hline Length of oxygen therapy within $7 \mathrm{~d}$ after extubation & $5.6 \pm 1.8^{*}$ & $5.9 \pm 1.6^{*}$ & $-0.3(-1.15$ to 0.49$)$ & .43 \\
\hline Length of ICU stay within $7 \mathrm{~d}$ after extubation & $4.4 \pm 1.8^{*}$ & $3.8 \pm 1.8^{*}$ & $0.6(-0.30$ to 1.46$)$ & .19 \\
\hline $\begin{array}{l}* \text { Mean } \pm \text { SD d. } \\
\text { HFNC }=\text { high-flow nasal cannula } \\
\text { Nebulizer = large volume nebulization-based humidifier } \\
\text { NIV = noninvasive ventilation }\end{array}$ & & & & \\
\hline
\end{tabular}

parameters $\left(\mathrm{pH}, \mathrm{P}_{\mathrm{aO}}, \mathrm{P}_{\mathrm{aCO}}\right.$, and arterial oxygen saturation), discomfort, and set $\mathrm{F}_{\mathrm{IO}_{2}}$ for respiratory status at 1,6 , 24, and $48 \mathrm{~h}$, and at 5 and $7 \mathrm{~d}$ after extubation. We evaluated discomfort on a scale of 0-10 by using the numerical rating scale or the faces pain scale. We also reported the following severe adverse events: death or life-threatening clinical features, extension of hospitalization period, persistent or prominent disability or dysfunction, and permanent disability and dysfunction due to the protocol treatment.

\section{End Points}

The primary end point was the re-intubation rate within $7 \mathrm{~d}$ after extubation. Secondary end points were $\mathrm{P}_{\mathrm{aO}_{2}} /$ set $\mathrm{F}_{\mathrm{IO}_{2}}$, length of ICU stay, and oxygen therapy within $7 \mathrm{~d}$ after extubation.

\section{Sample Size}

In the previous study by Maggiore et al, ${ }^{9}$ re-intubation was performed in 2 of 53 subjects $(3.8 \%)$ in the HFNC group and in 11 of 52 subjects $(21.2 \%)$ in the control group. The re-intubation rate in the HFNC group was thus decreased to 0.18 times that of the control group. Re-intubation rates of $3-19 \%$ have been reported. ${ }^{12}$ These rates vary according to the extubation protocol or patient population. In our department, the re-intubation rate for patients who received mechanical ventilation for $>24 \mathrm{~h}$ and had respiratory failure at extubation was $17.1 \%$ in the period from May 20, 2012, to April 30, 2013. Therefore, we hypothesized that the re-intubation rate could be decreased to $3.1 \%(0.18 \times 17.1 \%)$ in the intervention group. We calculated the sample size for testing this hypothesis. When the $\alpha$ error was set to 0.05 and the detection power was set to $80 \%$, the required number of cases was 86 in each group. We also estimated the number of eligible patients to be 60 per year and set the study period at 2 years and 8 months.

\section{Statistical Analysis}

The Fisher exact test was used to analyze categorical variables, including the primary end point. The Student $t$ test was used for between-group comparisons of continuous variables. Statistical significance was set at $P<$ .05. All analyses were performed by using R ver. 3.4.1 (R Foundation for Statistical Computing, Vienna, Austria). All analyses included only the subjects who had no missing data on the relevant variables.

\section{Results}

A total of 72 subjects were enrolled in this study between August 2015 and March 2018. We could not recruit enough subjects for the sample size we designed. After discussions with the steering committee, the study was discontinued because the time required to reach the target number would have been too long. We analyzed 69 subjects, 30 in the 


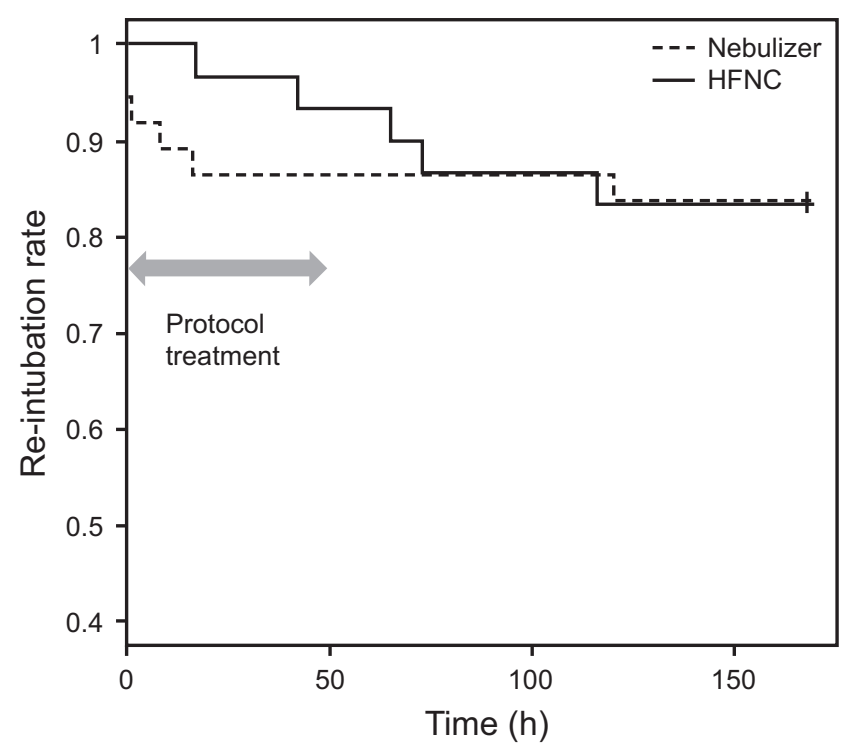

Fig. 2. Re-intubation rate in each group. HFNC = high-flow nasal cannula. $P=.97$, log-rank test.

HFNC group and 39 in the nebulizer group (Fig. 1). Characteristics of the subjects were similar between the two groups (Table 1). Of the subjects included in the analysis, the mean age was $72 \pm 18 \mathrm{y}$ in the HFNC group and $71 \pm 16 \mathrm{y}$ in the nebulizer group, and $75 \%$ had a Glasgow coma scale score of $<15$ within $3 \mathrm{~h}$ before extubation. The main cause of respiratory failure was pneumonia (56\%), and the mean duration of mechanical ventilation was $6 \mathrm{~d}$. Twenty subjects (29\% of total) had hypercapnic respiratory failure. The mean $\mathrm{P}_{\mathrm{aO}} / \mathrm{F}_{\mathrm{IO}_{2}}$ within $3 \mathrm{~h}$ before extubation was $221 \mathrm{~mm} \mathrm{Hg}$.

The re-intubation rate within $7 \mathrm{~d}$ was not significantly different between the HFNC versus nebulizer groups $(5 / 30$ subjects $[17 \%]$ vs $6 / 39$ subjects $[15 \%], P>.99)$. The length of ICU stay and oxygen therapy within $7 \mathrm{~d}$ were also not significantly different (Table 2). The timing of re-intubation tended to be later in the HFNC group (Fig. 2). The most common indication for re-intubation was desaturation or atelectasis due to ineffective airway clearance ( 2 in the HFNC group, 3 in the nebulizer group) (Table 2). $\mathrm{P}_{\mathrm{aO}} / \mathrm{set}_{\mathrm{IO}_{2}}$ showed the greatest difference within $24 \mathrm{~h}$ after extubation between the groups, but no statistical significance was observed (mean \pm SD, $264 \pm$ $105 \mathrm{~mm} \mathrm{Hg}$ in the HFNC group vs $224 \pm 53 \mathrm{~mm} \mathrm{Hg}$ in the nebulizer group; $P=.07$ ) (Fig. 3).

In a subsequent exploratory analysis, the $\mathrm{P}_{\mathrm{aO}} / \mathrm{set}_{\mathrm{IO}_{2}}$ in the subgroup with a duration of mechanical ventilation $<7$ $\mathrm{d}$ was significantly higher in the HFNC group than in the nebulizer group at $24 \mathrm{~h}$ and $48 \mathrm{~h}$ after extubation (at $24 \mathrm{~h}$ : $270 \mathrm{~mm} \mathrm{Hg}$ vs $220 \mathrm{~mm} \mathrm{Hg}[P=.045]$; at $48 \mathrm{~h}: 329 \mathrm{~mm}$ $\mathrm{Hg}$ vs $243 \mathrm{~mm} \mathrm{Hg}[P=.048]$ ) (Table 3 ). The degree of discomfort experienced during the protocol treatments was not significantly different between the two groups, but there were many missing values ( $21 \%$ of total) (Table 4$)$. One severe adverse event was recorded after protocol treatment in the HFNC group (cardiac arrest due to airway obstruction by a mucus plug).

\section{Discussion}

Although several clinical studies investigated HFNC therapy after extubation, ${ }^{9,13-16}$ to our knowledge, this is the first randomized controlled trial of HFNC in the postextubation management of adult subjects who were critically ill in comparison with the routine use of a heated humidifier in the control group. This study was discontinued when $40 \%$ of the planned sample size was enrolled because reaching the target number of subjects was judged to be difficult. However, the primary outcome was almost the same in both groups at the time of discontinuation. Because the sample size we calculated was unlikely to yield a

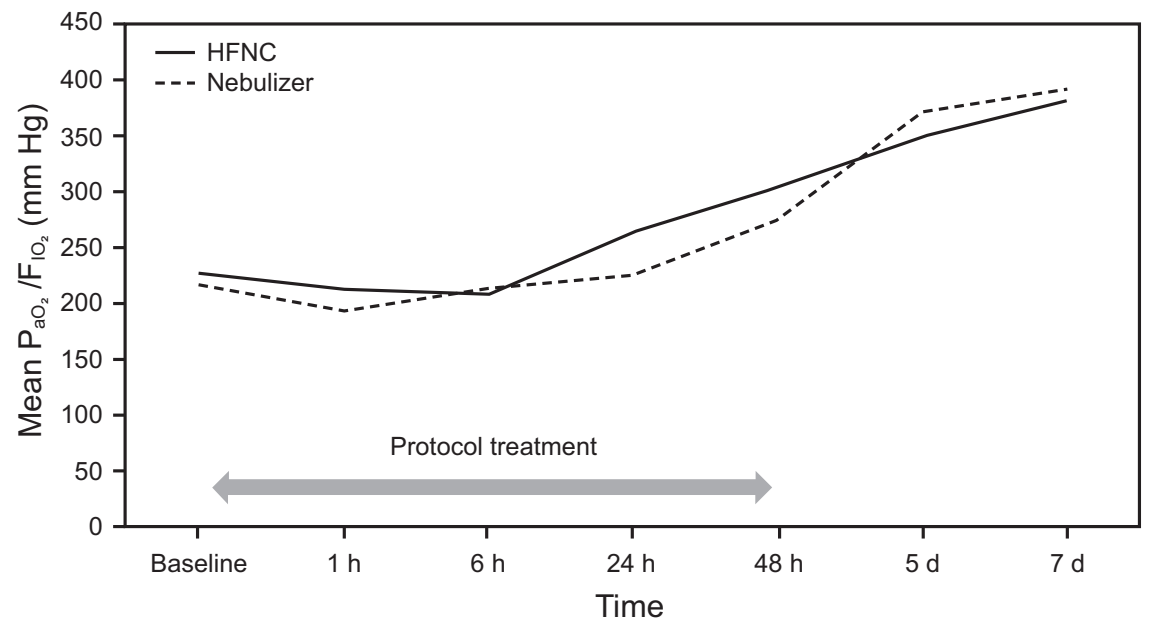

Fig. 3. Set $\mathrm{P}_{\mathrm{aO}_{2}} / \mathrm{F}_{\mathrm{IO}_{2}}$ for each group. $\mathrm{HFNC}=$ high-flow nasal cannula. 
Table 3. $\mathrm{P}_{\mathrm{aO}_{2}} / \mathrm{set} \mathrm{F}_{\mathrm{IO}_{2}}$ in the Subgroup of the Duration of Mechanical Ventilation

\begin{tabular}{|c|c|c|c|}
\hline $\begin{array}{c}\text { Duration of } \\
\text { Mechanical Ventilation }\end{array}$ & $n$ & $\begin{array}{l}\text { Median }(\mathrm{mm} \mathrm{Hg}) \\
\quad(\min , \max )\end{array}$ & $\begin{array}{l}\text { Difference }(\mathrm{mm} \mathrm{Hg}) \\
\quad(\min , \max )\end{array}$ \\
\hline \multicolumn{4}{|l|}{$<7 \mathrm{~d}$} \\
\hline \multicolumn{4}{|l|}{ HFNC } \\
\hline Before extubation & 22 & $228(171,327)$ & \\
\hline \multicolumn{4}{|l|}{ After extubation } \\
\hline $1 \mathrm{~h}$ & 22 & $200(118,323)$ & $-25(-83,71)$ \\
\hline $6 \mathrm{~h}$ & 22 & $199(114,370)$ & $-18(-137,103)$ \\
\hline $24 \mathrm{~h}$ & 21 & $270(168,523)$ & $29(-60,260)$ \\
\hline $48 \mathrm{~h}$ & 21 & $329(168,507)$ & $90(-66,256)$ \\
\hline \multicolumn{4}{|l|}{ Nebulizer } \\
\hline Before extubation & 22 & $225(140,303)$ & \\
\hline \multicolumn{4}{|l|}{ After extubation } \\
\hline $1 \mathrm{~h}$ & 22 & $204(120,335)$ & $-28(-72,136)$ \\
\hline $6 \mathrm{~h}$ & 21 & $227(126,342)$ & $2(-99,106)$ \\
\hline $24 \mathrm{~h}$ & 18 & $220(140,339)$ & $1(-97,111)$ \\
\hline $48 \mathrm{~h}$ & 17 & $243(126,441)$ & $29(-74,170)$ \\
\hline \multicolumn{4}{|l|}{$\geq 7 \mathrm{~d}$} \\
\hline \multicolumn{4}{|l|}{ HFNC } \\
\hline Before extubation & 8 & $221(153,290)$ & \\
\hline \multicolumn{4}{|l|}{ After extubation } \\
\hline $1 \mathrm{~h}$ & 8 & $204(108,264)$ & $-23(-98,57)$ \\
\hline $6 \mathrm{~h}$ & 8 & $164(150,243)$ & $-2(-78,8)$ \\
\hline $24 \mathrm{~h}$ & 8 & $173(113,306)$ & $-41(-120,141)$ \\
\hline $48 \mathrm{~h}$ & 7 & $188(143,407)$ & $-10(-84,241)$ \\
\hline \multicolumn{4}{|l|}{ Nebulizer } \\
\hline Before extubation & 16 & $218(156,284)$ & \\
\hline \multicolumn{4}{|l|}{ After extubation } \\
\hline $1 \mathrm{~h}$ & 15 & $164(102,254)$ & $-55(-124,40)$ \\
\hline $6 \mathrm{~h}$ & 14 & $202(122,291)$ & $-20(-132,74)$ \\
\hline $24 \mathrm{~h}$ & 12 & $223(108,303)$ & $2(-88,74)$ \\
\hline $48 \mathrm{~h}$ & 13 & $292(191,329)$ & $52(-65,205)$ \\
\hline \multicolumn{4}{|c|}{$\begin{array}{l}\text { HFNC }=\text { high-flow nasal cannula } \\
\text { Nebulizer }=\text { a large-volume nebulization-based humidifier } \\
\min =\text { minimum } \\
\max =\text { maximum }\end{array}$} \\
\hline
\end{tabular}

significant difference, we believe that the discontinuation of this study was valid. Due to early discontinuation, we could not achieve sufficient power to demonstrate that there was no difference between the two groups. We believe that large exploratory studies will be needed to analyze whether a true difference exists between the re-intubation rates.

The American Thoracic Society recommends that the initial SBT be carried out with inspiratory pressure augmentation $\left(5-8 \mathrm{~cm} \mathrm{H}_{2} \mathrm{O}\right)$ for patients on mechanical ventilation for $>24 \mathrm{~h}^{17}$; however, we administered the SBT with continuous positive airway pressure or T-piece based on recommendations of the Japanese academic societies (https://www. jsicm.org/pdf/kokyuki_ridatsu1503b.pdf, Accessed March 10, 2019). The re-intubation rate within $48 \mathrm{~h}$ in the nebulizer group in this study was $13 \%$, consistent with the findings of a previous study. ${ }^{12}$
Table 4. Comparisons of Discomfort

\begin{tabular}{llccc}
\hline \hline $\begin{array}{c}\text { Area of } \\
\text { Discomfort }\end{array}$ & $\begin{array}{c}\text { HFNC Group, } \\
\text { median (25-75\%) } \\
(n=30)\end{array}$ & $\begin{array}{c}\text { Nebulizer Group, } \\
\text { median }(25-75 \%) \\
(n=39)\end{array}$ & $P$ & $\begin{array}{c}\text { Missing } \\
\text { Data, } \\
n / N(\%)\end{array}$ \\
\hline At 1 h & & & & \\
Nasal & $0(0-4.5)$ & $0(0-2.5)$ & .78 & $14 / 68(21)$ \\
Oral & $0(0-3)$ & $0(0-3)$ & .94 & $14 / 68(21)$ \\
Pharynx & $1(0-4)$ & $2(0-4.5)$ & .44 & $14 / 68(21)$ \\
At 6 h & & & & \\
Nasal & $0(0-2)$ & $0(0-3)$ & .92 & $10 / 65(15)$ \\
Oral & $0(0-2)$ & $0(0-3)$ & .82 & $10 / 65(15)$ \\
Pharynx & $0(0-3.5)$ & $1.5(0-4.0)$ & .87 & $10 / 65(15)$ \\
At 24 h & & & & \\
Nasal & $0(0-2.75)$ & $1(0-3.0)$ & .27 & $12 / 50(24)$ \\
Oral & $0(0-2)$ & $0.5(0-3)$ & .56 & $12 / 50(24)$ \\
Pharynx & $0(0-2.75)$ & $3(0-5.0)$ & .65 & $12 / 50(24)$ \\
At 48 h & & & & \\
Nasal & $0(0-3.75)$ & $0(0-1.5)$ & .93 & $6 / 20(30)$ \\
Oral & $0(0-3)$ & $0(0-3)$ & .84 & $6 / 20(30)$ \\
Pharynx & $0(0-4.5)$ & $0(0-1.5)$ & .87 & $6 / 20(30)$ \\
\hline Faces pain scale or numerical rating scale, $0-10$. & & & \\
This analysis used the Mann-Whitney U test. & & & \\
HFNC = high-flow nasal cannula & & & \\
Nebulizer = large-volume nebulization-based humidifier & & \\
\hline
\end{tabular}

This study included subjects who were hypercapnic. However, because we carried out the SBT without inspiratory pressure augmentation, the patients who required noninvasive ventilation shortly after extubation due to severe respiratory acidosis were not enrolled. This study could not demonstrate the superiority of HFNC. This was in contrast to the results of studies by Maggiore et $\mathrm{al}^{9}$ and Hernández et al, ${ }^{10}$ which showed that HFNC reduced the re-intubation rate. Therefore, we believe that there are several other reasons besides the lack of statistical power.

First, the effect of ineffective airway clearance may have been reduced equally in both groups due to the heated humidifier. There was no significant difference in the re-intubation rate due to airway failure. Second, compared with previous studies, our study population included subjects who were older or who had been on mechanical ventilation for a longer duration. ${ }^{9}{ }^{910}$ For such patients with prolonged mechanical ventilation, the reason for re-intubation is often airway failure. ${ }^{18}$ Therefore, differences due to oxygen therapy might be unlikely in this study. Furthermore, the increased $\mathrm{P}_{\mathrm{aO}} / \mathrm{set}_{\mathrm{IO}_{2}}$ noted in the HFNC group was observed in only those with a short duration of mechanical ventilation. It is likely that the effectiveness of HFNC may be lost due to the longer duration of mechanical ventilation, but our data are as yet insufficient to prove this.

Third, although most previous studies compared the reintubation rate within $48-72 \mathrm{~h},{ }^{9,10,15,16}$ we used a cutoff of within $7 \mathrm{~d}$ in this study. Extubation failure is defined as re- 
intubation within $48 \mathrm{~h}$ after extubation. ${ }^{12}$ However, HFNC has a higher automated $\mathrm{F}_{\mathrm{IO}_{2}}$ setting than conventional oxygen therapy and maintains a mild positive airway pressure. Therefore, it may be possible to prevent re-intubation temporarily, even if the patient's condition subsequently worsens. Delayed re-intubation when using HFNC is associated with poor prognosis, ${ }^{19}$ so we considered that a longer observation period was necessary. Because of this longer period, 3 subjects were re-intubated after the protocol treatment in the HFNC group and the re-intubation rate within 7 $\mathrm{d}$ was equivalent in both groups.

Few randomized controlled trials compared HFNC with conventional oxygen therapy in terms of the re-intubation rate within $7 \mathrm{~d}$. Futier et al ${ }^{20}$ compared HFNC with conventional oxygen therapy for patients after major abdominal surgery but found no significant difference in the re-intubation rate after $7 \mathrm{~d}$. A meta-analysis showed that HFNC decreased the re-intubation rate but did not improve ICU mortality, ${ }^{21}$ which suggests that the preventive effect of HFNC therapy against re-intubation is temporary and that respiratory status should be monitored after using HFNC.

As the benefit of HFNC oxygen therapy, the high flow have been emphasized, however, the effect of heated humidifier may be also important. Unlike previous studies that compared various forms of oxygen therapy without a heated humidifier, ${ }^{9,10}$ this study used a large-volume nebulization-based humidifier as a control and did not find a decrease in the re-intubation rate due to airway failure in the HFNC group. Therefore, the main factor in reducing the re-intubation rate due to airway failure may be humidification, not high flow.

In this study, which may have included many subjects at high risk of airway failure, HFNC did not reduce the reintubation rate within $7 \mathrm{~d}$. Furthermore, no improvement in $\mathrm{P}_{\mathrm{aO}} / \mathrm{set}_{\mathrm{IO}_{2}}$ was seen in the subgroup with prolonged mechanical ventilation. Similarly, another study that targeted subjects at high risk and after extubation found that HFNC was not significantly superior to conventional oxygen therapy. ${ }^{16}$ We suggest that the indications for HFNC in patients at high risk be carefully reconsidered.

This study had several limitations other than the small sample size and low recruitment rate. First, we did not examine the amount of sputum and severity of cough. Therefore, we could not confirm whether ineffective airway clearance at baseline was equivalent in both groups. However, the subjects were not extubated if there was no cough reflex because we assessed the airway risk of all subjects before extubation based on recommendations of academic societies in Japan (https://www.jsicm.org/pdf/ kokyuki_ridatsu1503b.pdf, Accessed March 10, 2019). We also could not evaluate whether the performance of the heated humidifier in both devices was equivalent.

As an alternative, we evaluated the degree of discomfort caused by the protocol treatments. In a previous study, ${ }^{9}$
HFNC therapy was found to be more comfortable compared with the air-entrainment mask. Although there were some missing data due to the subjects' altered consciousness from conditions such as dementia and delirium, there was little discomfort and no significant difference between the two groups in the present study. Thus, we successfully prevented drying of the airway and facilitated airway clearance in both groups. It has been reported that humidification with low-flow oxygen therapy increases the risk of infections and does not improve respiratory status ${ }^{22}$; however, we could not collect data on infection as an adverse event. Also, we used a conventional nasal cannula that was not humidified when set $\mathrm{F}_{\mathrm{IO}_{2}}$ was $\leq 0.3$. Therefore, we believe that the aerosol was more beneficial than harmful to the subjects in our protocol.

\section{Conclusions}

Compared with a large-volume nebulization-based humidifier, oxygen therapy via HFNC may not reduce the re-intubation rate of subjects with respiratory failure within $7 \mathrm{~d}$ after extubation. However, because of insufficient statistical power, further studies are needed to reach a conclusion.

\section{REFERENCES}

1. Chikata Y, Onodera M, Oto J, Nishimura $\mathrm{M}$. $\mathrm{FIO}_{2}$ in an adult model simulating high-flow nasal cannula therapy. Respir Care 2017;62(2): 193-198.

2. Spencer KT, Kimura BJ, Korcarz CE, Pellikka PA, Rahko PS, Siegel RJ. Focused cardiac ultrasound: recommendations from the American Society of Echocardiography. J Am Soc Echocardiogr 2013;26(6): 567-581.

3. Vargas F, Saint-Leger M, Boyer A, Bui NH, Hilbert G. Physiologic effects of high-flow nasal cannula oxygen in critical care subjects. Respir Care 2015;60(10):1369-1376.

4. Delorme M, Bouchard PA, Simon M, Simard S, Lellouche F. Effects of high-flow nasal cannula on the work of breathing in patients recovering from acute respiratory failure. Crit Care Med 2017;45(12):19811988.

5. Mauri T, Alban L, Turrini C, Cambiaghi B, Carlesso E, Taccone P, et al. Optimum support by high-flow nasal cannula in acute hypoxemic respiratory failure: effects of increasing flow rates. Intensive Care Med 2017;43(10):1453-1463.

6. Corley A, Caruana LR, Barnett AG, Tronstad O, Fraser JF. Oxygen delivery through high-flow nasal cannulae increase end-expiratory lung volume and reduce respiratory rate in post-cardiac surgical patients. Br J Anaesth 2011;107(6):998-1004.

7. Parke RL, McGuinness SP, Eccleston ML. A preliminary randomized controlled trial to assess effectiveness of nasal high-flow oxygen in intensive care patients. Respir Care 2011;56(3):265-270.

8. Parke R, McGuinness S, Dixon R, Jull A. Open-label, phase II study of routine high-flow nasal oxygen therapy in cardiac surgical patients. Br J Anaesth 2013;111(6):925-931.

9. Maggiore SM, Idone FA, Vaschetto R, Festa R, Cataldo A, Antonicelli F, et al. Nasal high-flow versus Venturi mask oxygen therapy after extubation. Effects on oxygenation, comfort, and clinical outcome. Am J Respir Crit Care Med 2014;190(3):282-288. 


\section{HFNC vs Heated Humidity Postextubation}

10. Hernández G, Vaquero C, González P, Subira C, Frutos-Vivar F, Rialp G, et al. Effect of post-extubation high-flow nasal cannula vs conventional oxygen therapy on re-intubation in low-risk patients: a randomized clinical trial. JAMA 2016;315(13):1354-1361.

11. Branson RD. Secretion management in the mechanically ventilated patient. Respir Care 2007;52(10):1328-1342; discussion 1342-1327.

12. Boles JM, Bion J, Connors A, Herridge M, Marsh B, Melot C, et al. Weaning from mechanical ventilation. Eur Respir J 2007;29(5):10331056.

13. Rittayamai N, Tscheikuna J, Rujiwit P. High-flow nasal cannula versus conventional oxygen therapy after endotracheal extubation: a randomized crossover physiologic study. Respir Care 2014;59 (4):485-490

14. Brotfain E, Zlotnik A, Schwartz A, Frenkel A, Koyfman L, Gruenbaum SE, Klein M. Comparison of the effectiveness of high flow nasal oxygen cannula vs. standard non-rebreather oxygen face mask in post-extubation intensive care unit patients. Isr Med Assoc J 2014;16(11):718-722.

15. Song HZ, Gu JX, Xiu HQ, Cui W, Zhang GS. The value of high-flow nasal cannula oxygen therapy after extubation in patients with acute respiratory failure. Clinics (Sao Paulo) 2017;72(9):562-567.

16. Fernandez R, Subira C, Frutos-Vivar F, Rialp G, Laborda C, Masclans JR, et al. High-flow nasal cannula to prevent postextubation respiratory failure in high-risk non-hypercapnic patients: a randomized multicenter trial. Ann Intensive Care 2017;7(1):47.
17. Schmidt GA, Girard TD, Kress JP, Morris PE, Ouellette DR, Alhazzani W, et al. Liberation from mechanical ventilation in critically ill adults: executive summary of an official American College of Chest Physicians/American Thoracic Society Clinical Practice Guideline. Chest 2017;151(1):160-165.

18. Jaber S, Quintard H, Cinotti R, Asehnoune K, Arnal JM, Guitton C, et al. Risk factors and outcomes for airway failure versus non-airway failure in the intensive care unit: a multicenter observational study of 1514 extubation procedures. Crit Care 2018;22(1):236.

19. Kang BJ, Koh Y, Lim CM, Huh JW, Baek S, Han M, et al. Failure of high-flow nasal cannula therapy may delay intubation and increase mortality. Intensive Care Med 2015;41(4):623-632.

20. Futier E, Paugam-Burtz C, Godet T, Khoy-Ear L, Rozencwajg S, Delay JM, et al. Effect of early postextubation high-flow nasal cannula vs conventional oxygen therapy on hypoxaemia in patients after major abdominal surgery: a French multicentre randomised controlled trial (OPERA). Intensive Care Med 2016;42(12):1888-1898.

21. Ni YN, Luo J, Yu H, Liu D, Ni Z, Cheng J, et al. Can high-flow nasal cannula reduce the rate of endotracheal intubation in adult patients with acute respiratory failure compared with conventional oxygen therapy and noninvasive positive pressure ventilation?: a systematic review and meta-analysis. Chest 2017;151(4):764-775.

22. Wen Z, Wang W, Zhang H, Wu C, Ding J, Shen M. Is humidified better than non-humidified low-flow oxygen therapy? A systematic review and meta-analysis. J Adv Nurs 2017;73(11):2522-2533.

This article is approved for Continuing Respiratory Care Education credit. For information and to obtain your CRCE

(free to AARC members) visit www.rcjournal.com 